\title{
The effect of hCG, GnRH and PGF analogue cloprostenol on the oestrus cycle in jennies
}

\author{
Eliška Horáčková, Miroslava Mráčková, Michal Vyvial, Šárka Krisová, Markéta Sedlinská \\ University of Veterinary and Pharmaceutical Sciences Brno, \\ Faculty of Veterinary Medicine, Equine Clinic Brno, Czech Republic \\ Received November 28, 2018 \\ Accepted June 13, 2019
}

\begin{abstract}
The objectives of this study were twofold. Firstly, the present study was designed to examine susceptibility of the corpus luteum (CL) in early diestrus in jennies; and secondly, to investigate the effect of two commonly used hormonal agents in horses on the induction of ovulation in jennies. The oestrus cycles of eleven jennies were monitored by ultrasound every day. When the dominant follicle reached a diameter of $30 \mathrm{~mm}$, the jennies were treated by intramuscular administration of gonadotropin-releasing hormone agonist lecirelin ( $\mathrm{GnRH}, 50 \mu \mathrm{g}$ pro toto) in the first oestrus cycle, and human chorionic gonadotropin (hCG, 1500 IU pro toto) intramuscularly in the second oestrus cycle. Prostaglandin $\mathrm{F}_{2 \alpha}$ analogue cloprostenolum ( $\mathrm{PGF}_{2 \alpha}, 0.125 \mathrm{mg}$ pro toto) was administered intramuscularly 2 days after the first ovulation and the interovulatory interval was monitored. This study showed that intramuscular administration of $50 \mu \mathrm{g}$ of GnRH agonist lecirelin resulted in ovulation within $48 \mathrm{~h}$ in $73 \%$ of treated jennies. Intramuscular administration $1500 \mathrm{IU}$ of hCG was found to be poorly effective to induce ovulation, with $36 \%$ of animals ovulating within $48 \mathrm{~h}$. Intramuscular administration of $\mathrm{PGF}_{2 \alpha}$ analogue cloprostenol 2 days after ovulation was unsuccessful in attempting to shorten the interovulatory interval in donkeys.
\end{abstract}

Donkey, induction of ovulation, luteolysis

Interest in donkey reproduction has been on the rise recently. Compared to horses, knowledge about management of the oestrus cycle in the donkey is limited. The lack of information about hormonal manipulation of the oestrus cycle in donkeys can seriously reduce the efficiency of assisted reproduction techniques.

The oestrus cycle in jennies lasts 24 days on average (Blanchard et al. 1999; Taberner et al. 2008; Galisteo and Perez-Marin 2010; Quaresma and Payan-Carreira 2015; Díaz-Duran et al. 2017). The length of oestrus is similar to that in mares, while diestrus is longer in donkeys (Vandeplassche et al. 1981; Ginther et al. 1987; Blanchard et al. 1999; Contri et al. 2014). The length of oestrus is in the range of $5.9 \pm 2.1$ days (Blanchard et al. 1999), $5.64 \pm 0.20$ days (Taberner et al. 2008) and $6.5 \pm 0.6$ days (Contri et al. 2014). While the diestrus length ranges from $17.4 \pm 2.6$ days (Blanchard et al. 1999), $19.83 \pm 0.36$ (Taberner et al. 2008), and $16.8 \pm 0.6$ days (Contri et al. 2014). Ovulation usually occurs 1-2 days before the end of oestrus behaviour (Henry et al. 1987, Meira et al. 1995, Blanchard et al. 1999).

The average size of the preovulatory follicle may be breed-dependent. Reported mean diameters of the preovulatory follicles are $44.9 \pm 0.5 \mathrm{~mm}$ in the Catalonian (Taberner et al. 2008), $43.7 \pm 0.13 \mathrm{~mm}$ in the Martina Franca donkey breed (Contri et al. 2014), $41.3 \pm 1.3 \mathrm{~mm}$ in French jennies (Dadarwal et al. 2004) and $36.9 \pm 0.7 \mathrm{~mm}$ in the "Mexican Burro" donkeys (Díaz-Duran et al. 2017). Follicular dominance is established at a diameter of about $25 \mathrm{~mm}$. Most dominant follicles are about $27 \mathrm{~mm}$ in diameter at the onset of oestrus. Follicular growth averages $2.7 \mathrm{~mm}$ per day (Dadarwal et al. 2004). 
Synchronization of the jennies' oestrus cycle is possible using exogenous PGF $_{2 \alpha}$, primarily as a luteolytic agent to induce oestrus. The earlier oestrus can be induced the better for an effective reproductive management of the jenny. A study of Nigerian jennies established that a double treatment of naturally occurring prostaglandin $\mathrm{PGF}_{2 \alpha}$ (dinoprost) as tromethamine salt had a better response and therefore was more efficient than a single treatment in oestrus synchronization (Hassan et al. 2017). On the other hand, Carluccio et al. (2008) reported findings which indicate that a single $\mathrm{PGF}_{2 \alpha}$ R-cloprostenol treatment on day 3 post-ovulation caused the functional regression of corpus luteum (CL) in the jenny, evidenced by both the rapid induction of oestrus and ovulation, and by an abrupt drop in circulating plasma progesterone concentration. They recorded an interovulatory interval of 9.6 days, indicating a marked reduction in the oestrous cycle length. Shortening the oestrus cycle has important implications for reproduction management programs in which insemination needs to be accurately timed (Carluccio et al. 2008). These results are contrary to the notion that the CL is insensitive to prostaglandins in the first 5 days after ovulation. In recent studies in horses, it has been observed that cloprostenol treatment during the post-ovulatory period ( $0-2$ days) induces a decrease in progesterone concentrations over days 5-7 post-treatment, followed by the recovery of progesterone levels and normal diestrus stage (Troedss on et al. 2001; Brendemuehl 2002; Nie et al. 2003). These findings suggest that cloprostenol could cause luteal "injury" or incomplete lysis when administered in early diestrus (Troedsson et al. 2001; Brendemuehl 2002; Nie et al. 2003) and could reflect the still incomplete susceptibility of CL such that it is only capable of a partial response to treatment. There is a need for further investigation focussing on $\mathrm{CL}$ responsiveness to $\mathrm{PGF}_{2 \alpha}$ given to donkeys in early diestrus.

The hormonal agents commonly used for the induction of ovulation in mares are human chorionic gonadotropin (hCG) and gonadotropin-releasing hormone (GnRH). The efficacy of hCG and $\mathrm{GnRH}$ for inducing ovulation in jennies has been reported by a few authors (Carluccio et al. 2007; Camillo et al. 2014). Human chorionic gonadotropin is a hormone the biological activity of which is similar to the luteinizing hormone (LH). The effects of hCG in hastening ovulation in mares has been previously studied, and the results revealed that the duration of oestrus and the treatment to ovulation interval was significantly reduced (Barb acini et al. 2000). However, it is well known that the effectiveness of hCG is reduced by successive injections in mares (Duchamp et al. 1987). An alternative method for inducing ovulation in mares is the use of GnRH agonists, such as buserelin, deslorelin, or lecirelin. Carluccio et al (2007) reported that even if hCG administration is the most efficient method for prediction and synchronization of ovulation, current results indicate that, unlike in the mare, even a single administration of lecirelin ( $\mathrm{GnRH}$-analogue) can successfully hasten ovulation in jennies where a follicle equal to larger than $30 \mathrm{~mm}$ has been detected. The study from Camillo et al. (2014) showed the possibility of inducing ovulation in jennies between 24 and $48 \mathrm{~h}$ with a single subcutaneous injection of a very low dose of GnRH agonist buserelin. The effect of a single administration of $\mathrm{GnRH}$ analogue lecirelin in the jenny differs from that reported in the mare (Carluccio et al. 2007). In mares, several studies demonstrated the inefficacy of only one or two administrations of GnRH (Duchamp et al. 1987; Camillo et al. 2004).

The aim of this study was to evaluate the response of CL to a single dose of $\mathrm{PGF}_{2 \alpha}$ analogue cloprostenol administered 2 days after ovulation. The second aim was to evaluate the effect on induction of ovulation by a single intramuscular (i.m.) dose of a $\mathrm{GnRH}$ analogue lecirelin in comparison with a single i.m. dose of hCG.

\section{Materials and Methods}

This study was carried out from May to August 2018 at the Equine Clinic, University of Veterinary and Pharmaceutical Sciences Brno. The experimental design was approved by the Ministry of Education, Youth and Sports (MSMT-11921 / 2017-5). 
Eleven jennies without previous hormonal therapy, 4-15 years old, were successively presented for this trial. All jennies were observed as being clinically healthy, in good body condition, and were kept in individual boxes with open paddocks allowing freedom of movement throughout the whole trial. Feed with hay and water was provided ad libitum. Daily trans-rectal ultrasonographic observations were done for the detection of follicular dynamics. Detection of oestrus in jennies was done by teasing with a donkey stallion (mouth clapping, urination, vulvar activity). In the first oestrus cycle, once there was evidence of external symptoms of oestrus and of follicular diameter $30 \pm 1 \mathrm{~mm}$, all jennies were administered the $\mathrm{GnRH}$ agonist lecirelin i.m. (50 $\mu \mathrm{g}$ pro toto, Supergestran, Fatro, Bologna, Italy). Ovulation was monitored daily by ultrasonographic observation. The second day after ovulation PGF $_{2 \alpha}$ cloprostenolum i.m. (0.125 mg pro toto, Oestrophan, Bioveta, Ivanovice n. Hané, Czech Republic) was administered and the jennies continued to be monitored daily. In the second oestrus cycle, once there was evidence of external symptoms of oestrus and of a follicular diameter of $30 \pm 1 \mathrm{~mm}$, all jennies were administered hCG i.m. (1500 IU pro toto, Pregnyl, NV Organon, Oss, The Netherlands) and were also monitored daily until ovulation.

\section{Results}

The results are presented in Table 1. A positive response (ovulation within $48 \mathrm{~h}$ ) in jennies injected with GnRH agonist was detected in 8 out of 11 jennies (73\%). A positive response in jennies injected with hCG was detected in 3 out of 11 jennies (27\%). A positive response in jennies injected with $\mathrm{PGF}_{2 \alpha}$ (shortening of diestrus to less than 16 days) was detected in 4 out of 11 jennies $(36 \%)$.

Table 1. Results from daily examinations in jennies.

\begin{tabular}{|c|c|c|c|c|c|c|c|c|}
\hline Jenny & $\begin{array}{l}\text { FD GnRH } \\
(\mathrm{mm})\end{array}$ & $\begin{array}{l}\text { OV GnRH } \\
\text { (until hours) }\end{array}$ & $\begin{array}{l}\text { FD OV } 1 \\
(\mathrm{~mm})\end{array}$ & $\begin{array}{l}\text { IOV } \\
\text { (days) }\end{array}$ & $\begin{array}{l}\text { FD PGF } \\
\quad(\mathrm{mm})\end{array}$ & $\begin{array}{l}\text { FD hCG } \\
(\mathrm{mm})\end{array}$ & $\begin{array}{c}\text { OV hCG } \\
\text { (until hours) }\end{array}$ & $\begin{array}{l}\text { FD OV } 2 \\
(\mathrm{~mm})\end{array}$ \\
\hline 1 & $32 \times 34$ & 96 & $35 \times 38$ & 8 & $<20$ & $33 \times 33$ & $\begin{array}{c}\text { anovulatory } \\
\text { follicle }\end{array}$ & - \\
\hline 2 & $33 \times 37$ & 72 & $30 \times 40$ & 20 & $<20$ & $33 \times 38$ & 48 & $32 \times 39$ \\
\hline 3 & $33 \times 33$ & 48 & $32 \times 35$ & 5 & $<20$ & $32 \times 32$ & 120 & $39 \times 42$ \\
\hline 4 & $30 \times 33$ & 120 & $31 \times 35$ & 18 & $<20$ & $30 \times 33$ & $\begin{array}{l}\text { anovulatory } \\
\text { follicle }\end{array}$ & - \\
\hline 5 & $30 \times 35$ & 48 & $31 \times 38$ & 21 & $<20$ & $30 \times 35$ & 72 & $40 \times 44$ \\
\hline 6 & $30 \times 31$ & 48 & $33 \times 35$ & 26 & $<20$ & $30 \times 31$ & 96 & $34 \times 34$ \\
\hline 7 & $31 \times 32$ & 24 & $32 \times 35$ & 22 & $<20$ & $30 \times 30$ & 48 & $33 \times 36$ \\
\hline 8 & $32 \times 34$ & 48 & $34 \times 36$ & 19 & $<20$ & $32 \times 34$ & 72 & $31 \times 36$ \\
\hline 9 & $33 \times 35$ & 24 & $33 \times 35$ & 16 & $<20$ & $30 \times 32$ & 48 & $30 \times 36$ \\
\hline 10 & $31 \times 32$ & 48 & $34 \times 37$ & 8 & $<20$ & $31 \times 33$ & 120 & $35 \times 36$ \\
\hline 11 & $32 \times 34$ & 48 & $30 \times 38$ & 10 & $<20$ & $31 \times 34$ & 96 & $33 \times 33$ \\
\hline
\end{tabular}

FD GnRH - follicular diameter on time of administration GnRH; OV GnRH - ovulation after GnRH administration; FD OV 1 - follicular diameter before ovulation; IOV - interval between ovulation and administration of hCG; FD PG$\mathrm{F}_{2 \alpha}$ - follicular diameter on time of administration $\mathrm{PGF}_{2 \alpha} ; \mathrm{FD} \mathrm{hCG}$ - follicular diameter on time of administration hCG; OV hCG - ovulation after hCG application; FD OV $2-$ follicular diameter before ovulation

\section{Discussion}

In mares there is a long-standing belief that an early developing $\mathrm{CL}(<5$ days after ovulation) is not susceptible to $\mathrm{PGF}_{2 \alpha}$ (Lofstedt 1988). However, Bergfelt et al. (2006) discovered that a single dose of native prostaglandin $\mathrm{PGF}_{2 \alpha}$ treatment on the $3^{\text {rd }}$ day after ovulation resulted in structural and functional regression of the CL and hastened the interval to the next ovulation, despite post-treatment resurgences in progesterone in mares. The $\mathrm{CL}$ appears to be mature on the $3^{\text {rd }}$ day post ovulation also in jennies. Injection of $\mathrm{PGF}_{2 \mathrm{a}}$ $\mathrm{R}$-cloprostenol at this time induces regression of the $\mathrm{CL}$ and a return to oestrus (Carluccio 
et al. 2008). There is a need for examination of the luteolytic effect of $\mathrm{PGF}_{2 \alpha}$ as earliest after ovulation as possible.

In this study, $0.125 \mathrm{mg}$ of cloprostenolum was administered i.m. 2 days after ovulation to investigate the susceptibility of CL in early diestrus. Shortening the interovulatory interval of the jenny may be useful in reproductive management, because diestrus in donkeys is longer than in horses. An earlier onset of oestrus was observed in 4 jennies from 11 (36\%). It seems that the partial failure to hasten oestrus and ovulation with a $\mathrm{PGF}_{2 \alpha}$ treatment 2 days after ovulation was due to a partial or incomplete luteolysis and resurgence of progesterone. Nie et al. (2003) reported that repeated administration of cloprostenol over $24 \mathrm{~h}$ in the early post-ovulatory period in mares may more effectively impair the luteal function than a single dose. In a recent study of Nigerian jennies, it was also established that the double treatment of naturally occurring prostaglandin PGF $_{2 \alpha}$ (dinoprost) had a better response in oestrus synchronization (Has san et al. 2017), but they did not mention when it was administered relative to the time of ovulation. It was suggested that a double treatment should be administered as early as $48 \mathrm{~h}$ after ovulation.

Induction of ovulation is another essential step in assisted reproduction. Accurate prediction of ovulation is invaluable for artificial insemination in donkeys as in horses. In a previous study, Carluccio et al. (2007) reported that, unlike in mares, even a single administration of lecirelin (GnRH-analogue) can successfully hasten ovulation in jennies. In their study a dose of $100 \mu \mathrm{g}$ of lecirelin was administered intravenously (i.v.). We found it much easier to administer i.m. instead of i.v. due to the donkey's behavioural issues. Jennies with follicles equal to or larger than $30 \mathrm{~mm}$ were treated with either lecirelin or hCG i.m. In this study, $50 \mu \mathrm{g}$ of lecirelin pro toto were administered i.m. and positive reactions (ovulation within $48 \mathrm{~h}$ ) were detected in $73 \%$ of the monitored jennies. These findings suggest that a lower single dose and an easier form of application of the GnRH analogue lecirelin can also successfully hasten ovulation in jennies.

Another result from the present study showed the ineffectiveness of hCG administered i.m. (1500 IU pro toto). In a recent study, Carluccio et al. (2007) treated jennies with hCG with a single i.v. injection of $2500 \mathrm{IU}$ hCG in two subgroups according to the follicular diameter (subgroup 30-35mm and subgroup 36-40 $\mathrm{mm}$ ). Ovulation occurred in the subgroups within $48 \mathrm{~h}$ in $92 \%$ and $100 \%$, respectively. This suggests that the follicular diameter at the time of administration being smaller than $35 \mathrm{~mm}$ was probably not the cause of failure. In order to shorten the interval to ovulation, we administered hCG i.m. at a follicular diameter $>30 \mathrm{~mm}$ and expected ovulation within $48 \mathrm{~h}$. Carluccio et al. (2007) suggested that the smaller follicles require a longer interval to ovulation compared to larger follicles, at the time of administration of hCG. Precise timing of ovulation induced by hormonal agents in jennies needs further investigation. Different methods of application, chosen due to behavioural issues, could be the reason. Different pharmacokinetics in donkeys have been described (Matthews et al. 2001; Matthews et al. 2002). In comparison with a dose of 2500 IU hCG i.v. when almost $100 \%$ ovulation was achieved (Carluccio et al. 2007), the dose of 1500 IU administered i.m. was essentially ineffective and will need to be further optimized. There are several reports that showed reduced efficacy of hCG after repeated use in the same season (Wilson et al. 1990; McCue et al. 2004). The use of GnRH agonists as an alternative method for inducing ovulation in jennies was considered.

In conclusion, this study demonstrated that a single dose $50 \mu \mathrm{g}$ of $\mathrm{GnRH}$ analogues lecirelin administered i.m. was able to induce ovulation in jennies within $48 \mathrm{~h}$. The dose of $1500 \mathrm{IU}$ of hCG administered i.m. proved to be poorly effective, with only $27 \%$ of animals ovulating within $48 \mathrm{~h}$. A single administration of the synthetic $\mathrm{PGF}_{2 \alpha}$ analogue cloprostenol 2 days after ovulation is not successful for shortening the interval to the next preovulatory follicle in jennies. 


\section{Acknowledgements}

The authors are grateful to IGA VFU Brno for the financial support of this research (114/2017/FVL, 109/2018/FVL).

\section{References}

Barbacini S, Zavaglia G, Gulden P, Marchi V, Necchi D 2000: Retrospective study on the efficacy of hCG in an equine artificial insemination programme using frozen semen. Equine Vet Educ 12: 312-317

Bergfelt DR, Pierson RA, Ginther OJ 2006: Regression and resurgence of the CL following PGF2alpha treatment 3 days after ovulation in mares. Theriogenology 65: 1605-1619

Blanchard TL, Taylor TS, Love CL 1999: Oestrous cycle characteristics and response to oestrus synchronization in mammoth assess (Equus asinus americanus). Theriogenology 52: 827-834

Brendemuehl JP 2002: Effect of oxytocin and cloprostenol on luteal formation, function and pregnancy rates in mares. Theriogenology 58: 623-626

Camillo F, Pacini M, Panzani D, Vannozzi I, Rota Al Aria G 2004: Clinical use of twice daily injections of buserelin acetate to induce ovulation in the mare. Vet Res Commun 28: 169-172

Camillo F, Vannozzi I, Tesi M, Sabatini CH, Rota A, Paciolla E, Danq-Nquyen I, Panzani D 2014: Induction of ovulation with buserelin in jennies: In search of the minimum effective dose. Anim Reprod Sci 151: 56-60

Carluccio A, Panzani S, Tosi U, Faustini M, De Amicis I, Veronesi MC 2007: Efficacy of hCG and GnRH for inducing ovulation in the jenny. Theriogenology 68: 914-919

Carluccio A, Panzani S, Contri A, Tosi U, De Amicis I, Veronesi MC 2008: Luteal function in jennies following PGF (2alpha) treatment 3 days after ovulation. Theriogenology 70: 121-125

Contri A, Robbe D, Gloria A, De Amicis I, Veronesi MC, Carluccio A 2014: Effect of the season on some aspects of the estrous cycle in Martina Franca donkey. Theriogenology 81: 657-661

Dadarwal D, Tandon SN, Purohit GN, Pareek PK 2004: Ultrasonographic evaluation of uterine involution and postpartum follicular dynamics in French jennies (Equus asinus) Theriogenology 62: 257-264

Díaz-Duran M, Zarco L, Boeta AM 2017: Ovarian dynamics and estrous cycle length in the donkey (Equus asinus). Theriogenology 103: 1-8

Duchamp G, Bour B, Combarnous Y, Palmer E 1987: Alternative solutions to hCG induction of ovulation in the mare. J Reprod Fertil Suppl 35: 221-228

Galisteo J, Perez-Marin CC 2010: Factors affecting gestation length and estrus cycle characteristics in Spanish donkey breeds reared in southern Spain. Theriogenology 74: 443-450

Ginther OJ, Scraba ST, Bergfelt DR 1987: Reproductive seasonality of the jennies. Theriogenology 27: 587-592

Hassan R, Rekwot PI, Bawa EK, Mohammed AK, Lawal M, Oke-Egbodo BE, Bello TK, Hussaini M, Umar U, Maikaji FS 2017: Comparative study on oestrus response using single and double tratment of PGF ${ }_{2 \alpha}\left(\right.$ Lutalyse $\left.^{\circledR}\right)$ in Nigerian jennies. J Anim Prof Res 29: 88-94

Henry M, Figueiredo AEF, Palhares MS, Coryn M 1987: Clinical and endocrine aspects of the oestrous cycle in donkeys (Equus asinus). J Reprod Fertil 35: 297-303

Lofstedt RM 1988: Control of the estrous cycle in the mare. Vet Clin North Am Equine Pract 4: 177-196

Matthews NS, Peck KE, Taylor TS, Mealey KL 2001: Pharmacokinetics of phenylbutazone and its metabolite oxyphenbutazone in miniature donkeys. Am J Vet Res 62: 673-675

Matthews NS, Taylor TS, Sullivan JA 2002: A comparison of three combinations of injectable anaesthetics in miniature donkeys. Vet Anaesth Analg 29: 36-42

McCue PM, Hudson JJ, Bruemmer JE, Squires EL 2004: Efficacy of hCG at inducing ovulation: a new look at an old issue. Proc Ann Conv Am Assoc Equine Pract 50: 510-513

Meira C, Ferreira JCP, Papa FO, Tornero MTT, Bicudo SD 1995: Study of the estrous cycle in donkeys (Equus asinus) using ultrasonography and plasma progesterone concentrations. Biol Reprod 1: 403-410

Nie GJ, Johnson KE, Wenzel JGW, Braden TD 2003: Luteal function mares following administration of oxytocin, cloprostenol or saline on Day 0, 1 or 2 post-ovulation. Theriogenology 60: 1119-1125a

Quaresma M, Payan-Carreira R 2015: Characterization of the estrous cycle of Asinina de Miranda jennies (Equus asinus). Theriogenology 83: 616-624

Taberner E, Medrano A, Peña A, Rigau T, Miró J 2008: Oestrus cycle characteristics and prediction of ovulation in Catalonian jennies. Theriogenology 70: 1489-1497

Troedsson MHT, Ababneh MM, Ohlgren AF, Madill S, Vetscher N, Gregas M 2001: Effect of periovulatory prostaglandin F2alpha on pregnancy rates and luteal function in the mare. Theriogenology 55: 891-899

Vandeplassche GM, Wesson JA, Ginther OJ 1981: Behavioral, follicular, and gonadotropin changes during the estrous cycle in donkeys. Theriogenology 16: 239-249

Wilson CG, Craig RD, Hughes PJ, Roser JF 1990: Effects of repeated hCG injections on reproductive efficiency in mares. J Equine Vet Sci 10: 301-308 